\title{
PHOSPHORUS COMPOUNDS IN FISH
}

\author{
H. L. A. TARR* \\ (Received November 2, 30)
}

For the past fifteen years active investigations concerning various aspects of occurrence and significance of phosphorus compounds in fish have been carried out by different scientists working in this laboratory. Since the time is limited I have taken the liberty of only describing in detail work which I have personally carried out, occasionally with the help of an assistant.

In 1949 the distribution of acid-soluble phosphorus compounds in muscles of several species of sea fish was investigated ${ }^{1}$. Glucose 1- and glucose 6-phosphates, adenine nucleotides, phosphocreatine, fructose phosphates, glycogen, "coenzyme" and pentose phosphate were found. At about this time interest developed in MAILLARD type of browning reactions in fish that occurred during heating and drying and this was shown to be largely due to ribose- (or glucose-) amino browning ${ }^{1)}$. Since ribose would obviously arise from a nucleic acid precursor, a study of some of the enzymes involved in nucleic acid metabolism in fish was initiated.

At the time these studies were started the enzymic sequence leading to postmortem formation of ribose was not known. The first enzyme that was studied was a riboside hydrolase prepared from muscle of Pacific lingcod, Ophiodon elongatus, or rock cod, Sebastodes species; it was purified about 1500 times $^{22}$. In this investigation and in subsequent studies on fish enzymes most procedures of separation have been conducted at $0-3^{\circ} \mathrm{C}$.

The purified enzyme hydorlyzed inosine at $\mathrm{pH} 8.6$ (optimum), and hydrolyzed adenosine, guanosine, inosine, xanthosine and cytidine, but not uridine, at pH 5.5 (optimum). It is possible that two different enzymes are involved. It was shown that a single enzyme is probably responsible for the various hydrolyses at $\mathrm{pH} 5.5$, and that the enzyme is definitely a nucleoside hydrolase, and not a nucleoside phosphorylase. D-Ribose and free bases were the products of the reaction. This enzyme is of interest in that it appears to be absent from muscle of Oncorhynchus salmon species, and very little free ribose develops post mortem in muscles of these fish. However, ribose is formed in significant amounts in muscle of Salmo gairdnerii post mortem. The enzyme withstood freeze drying. Recent work (unpublished) has shown that the enzyme will not hydrolyze deoxyribonucleosides. The presence of the enzyme may indicate a susceptibility to MaILLARD browning. The distribution of the enzyme

* Fisheries Research Board of Canada

(Invited paper for Symposium on Phosphorus Metabolism held by the Japanese Society of Scientific Fisheries at Shimizu, Japan, October 11, 1965) 
in other fish does not appear to have been studied.

It was later shown that the muscles of the above fish species also possess a ribonucleoside phosphorylase enzyme of quite wide specificity ${ }^{3)}$. This enzyme was much more labile than the nucleoside hydrolase, and only slight purification was obtained. The specific activity of purified preparations was 20 to $30 \mu$ moles of hypoxanthine utilized to form inosine per $\mathrm{mg}$ of protein $\mathrm{N}$ per hour at $37^{\circ} \mathrm{C}$. The equilibrium in the system: Hypoxanthine+ribose (or deoxyribose) 1-phosphate $\rightleftarrows$ inosine (or deoxy. inosine) +orthophosphate was about $85 \%$ in favour of nucleaside formation.

The enzyme was most active between $\mathrm{pH} 6$ and 7 , but was effective between about $\mathrm{pH} 5.5$ and 9.0. Only natural ribose 1-phosphate $(\alpha-\mathrm{RI}-\mathrm{P})$, or chemically synthetic $\alpha \cdot$ R1-P, supported nucleoside formation from hypoxanthine; $\beta$-RI-P and arabinose 1-P were inactive. In the presence of R1-P (or dR1-P) hypoxanthine, xanthine, 8 . azaguanine, 6-mercaptopurine and guanine were strongly activated, and adenine and 2,6-diaminopurine were less strongly activated. Purine, isoguanine, 2-aminopurine, 2 oxypurine, 2-mercaptopurine, 2-thioadenine, 2-thioguanine, 8-azaxanthine, 8-chloroxanthine, 8-aza-6-oxy-2-thiopurine, 4-amino-5-imidazole carboxamide, uric acid, uracil, cytosine and thymine were not utilized. Thus, the enzyme was specific for purines substituted in the C- 6 position and pyrimidines were not substrates. Both RI-P and dRl-P were activated by the same enzyme. The enzyme was partially inactivated by holding at $50^{\circ} \mathrm{C}$ for $300-420$ minutes, and withstood freeze-drying. It was unaffected by $\mathrm{Mg}^{++}, \mathrm{Ca}^{++}$and cysteine, or mixtures of these.

This enzyme is of interest in that it has been used by one biochemical manufacturing company to prepare deoxyribose 1-phosphate. In our own laboratory we have used it to make tritiated (radioactive) Rl-P and dR1-P from tritiated generally labeled nucleosides.

For some time it was thought that ribose in fish muscles was probably formed from ribonucleic acid (RNA) by post mortem enzymic degradation. This caused us to investigate the distribution of both RNA and DNA in muscles of different fish"). It was found that the muscles of six species of fish studied contained between 42 and $142 \mu \mathrm{g}$ of RNA and $0.2-2.5 \mu \mathrm{g}$ of DNA per $100 \mathrm{~g}$ (wet weight). The ratio of bases in the RNA was rather unusual averaging: adenine, 1.0; guanine, 2.0; cytosine, 1.0 and uracil, 1.25. So far, however, evidence accumulated in these laboratories by TomLinson and others indicates that naturally occurring fish muscle RNA is not degraded appreciably during normal post-mortem storage at cool temperatures, though crude commercial RNA is degraded when added to minced muscle. More recent studies (see below) indicate that free ribose probably arises largely from ATP, though the degradation of RNA may of course occur in species of fish not so far studied. The RNA may be linked to protein and thus be inaccessible to fish muscle nuclease.

MARTIN and TARR ${ }^{51}$ prepared phosphoglucomutase (PGM), phosphoribomutase (PRM) and phosphoglucoisomerase (PGI) from muscle of lingcod, Ophiodon elongatus. The 
procedure employed involved aqueous extraction, ammonium sulphate fractionation, heating to $55^{\circ} \mathrm{C}$ and chromatography on a DEAE cellulose column. In the purification procedure used PGI emerged first from the DEAE column and was fairly well separated from the PGM and PRM activities which emerged together as one "peak." In general the main "protein peaks" that emerged from the column did not correspond to the enzyme activities.

The fractions possessing PGM and PRM activities were pooled, but proved to be very unstable. They were completely inactivated by freezing and thawing and partially inactivated by holding overnight at $0^{\circ} \mathrm{C}$. The pooled eluate possessing PGI activity was found to be much more stable, and could be used for several days at $0^{\circ} \mathrm{C}$. Most of the studies on PGM and PRM were carried out using preparations partially purified by freeze-drying dialyzed, saturated ammonium-sulphate muscle extracts, flash heating these to $56^{\circ} \mathrm{C}$ and removing coagulated protein by centrifuging. The properties of these enzymes were investigated with the following results.

PGM was active between about $\mathrm{pH} 5.0$ and 9.0 and exhibited quite a sharp optimum at $\mathrm{pH}$ 7.5. PRM was active between $\mathrm{pH} 5.5$ and 9.5, and its optimum was about $\mathrm{pH}$ 8.0. PRI had a very wide range of activity between $\mathrm{pH}$ of about 5.5 and $>11.0$ with a general optimum between $\mathrm{pH} 8.0$ and 10.0 . The equilibrium in the system GIP: G6P as catalyzed by PGM was 5:95; that between RIP and R5P as catalyzed by PRM was 15:85. The equilibrium between G6-P and F6-P catalyzed by PGI was 38:62. All these values are quite similar to those reported for similar enzymes from other sources.

PGM required $\mathrm{Mg}^{++}$(optimum concentration $1 \times 10^{-3} M$ ) and cysteine (optimum concentration $1 \times 10^{-2} M$ ). PRM required neither $\mathrm{Mg}^{++}$nor cysteine; in fact they caused marked inhibition when present in concentrations above $1 \times 10^{-5}$ and $1 \times 10^{-3} \mathrm{M}$ respectively.

The "dephospho" form of PGM was prepared. It required addition of Gl, 6diphosphate (GDP), RDP or dRDP for activation, the effectiveness of these sugar phosphates being in the order given. PRM also required RDP, d-RDP or GDP for activity. It was not felt that sufficient evidence was available to suggest that PGM and PRM are different enzymes.

Since ample evidence has been presented in our own and in other laboratories that normal enzymes concerned in the EMBDEN-MYERHOF glycolytic pathway are present in fish muscles and other organs, it seemed of interest to determine whether fish contain enzymes of the hexosemonophosphate shunt or pentose phosphate pathway. Evidence had been presented in another laboratory that G6-P dehydrogenase and 6-phosphogluconic acid decarboxylase are present in fish liver, though no detailed study of these enzymes was carried out. However, it could be inferred that these enzymes could lead to formation of ribulose 5-phosphate (RU5-P). Two enzymes are required to transform this compound into substrates for transketolase. These are 
RU5-P 3'-epimerase (EPIM) which catalyzes formation of xylulose 5-P (XU5-P) (the donor), and phosphoriboisomerase, which catalyzes formation of R5-P (the acceptor aldehyde). Both these enzymes were prepared from lingcod muscle using a DEAE column in the final operation ${ }^{63}$.

PRI was purified about 2,000 times. Both PRI and EPIM had similar $\mathrm{pH}$ activity curves. They were active over a very wide range $(\mathrm{pH} 4.5$ to 11.0$)$ and had broad optima between about $\mathrm{pH} 7.5$ and 9.0. The equilibrium of the enzymes were established under several conditions with the following results: R5-P:RU5-P, 1.35:1.0; RU5-P:XU5-P, 1:1.5 and, with a mixture of both enzymes, R5-P $\rightleftarrows$ RU5-P $\rightleftarrows$ XU5-P, 1:0.58:0.66. The products of the various reactions were prepared and identified chemically. PRI was $45 \%$ inhibited by $5 \times 10^{-3} M$ phosphoribonic acid.

The discovery of the de novo scheme of purine nucleotide biosynthesis by BUCHANAN and collaborators, and of the key role played by 5-phosphoryl- $\alpha$-D-ribofuranose 1-pyrophosphate (PRPP, or P-ribose-PP) in this de novo scheme and in the direct synthesis of purine and pyrimidine nucleotides prompted a study of the formation of P-ribose-PP in fish tissues.

The lability of a cell-free enzyme forming P-ribose-PP from ATP and R5-P (5phosphorylribose 1-pyrophosphokinase) in fish muscle and organs was marked. The S.A. was 0.69 and 1.0 ( $\mu$ moles P-ribose-PP formed per $\mathrm{mg}$ protein per hour at $30^{\circ} \mathrm{C}$ ) with somewhat purified preparations from fish muscles. It was active between $\mathrm{pH}$

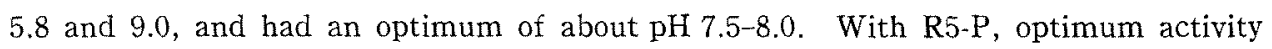
was obtained with a $5 \times 10^{-4} \mathrm{M}$ concentration and higher concentrations up to $5 \times 10^{-8} \mathrm{M}$ had no effect on activity. The optimum concentration of ATP was about $2.5 \times 10^{-3} \mathrm{M}$ and higher or lower concentrations reduced activity. The enzyme had an absolute requirement for $\mathrm{Mg}^{++}$ions with an optimum concentration of $2 \times 10^{-3} \mathrm{M}$. Although P-ribose-P.P formation proceeded in absence of added glutathione, the presence of this reducing agent was markedly stimulatory and this enhancement of activity increased up to $2 \times 10^{-2} M \mathrm{GSH}$. Higher concentrations were not studied. KF $(0.01$ to $0.1 M)$ about doubled activity. Tests indicated that the reaction: $\mathrm{R} 5-\mathrm{P}+\mathrm{ATP} \rightarrow \mathrm{P}$. ribose $\mathrm{PP}+\mathrm{Pi}$ is almost certainly irreversible. $\mathrm{P}$-ribose-PP was prepared in good yield using the lingcod muscle enzyme. $\mathrm{d}-\mathrm{R} 5 \mathrm{P}$ could not replace R5-P with the fish enzyme. These results show that the fish enzyme has properties very similar to those of the enzyme prepared from pigeon liver.

Several years ago certain deoxyribonucleic acid degrading enzymes were shown to be present in salmon kidney, and a nucleoside phosphorylase in salmon liver" Since this work was done, a very powerful DNAse II ("acid" DNAse) has been prepared from mature salmon testes elsewhere. Tests showed that all salmon tissues studied possessed DNAse activity at neutral $\mathrm{pH}$ values, kidney possessing greatest activity. For this reason protamine-treated kidney extracts were used as enzyme source. The protamine treatment removed RNA that could interfere with DNA hy. 
drolysis products. Obviously such preparations were very crude and could contain a neutral DNAse, a phosphodiesterase and phosphatases since deoxynucleosides and $\mathrm{Pi}$ were liberated.

Salmon DNA was prepared and incubated with the crude enzyme at $\mathrm{pH} 7.6$ and in presence of $0.02 \mathrm{M} \mathrm{Mg}^{++}$for 30 hours at $37^{\circ} \mathrm{C}$ under a layer of toluene with occasional shaking. By appropriate extraction and chromatographic methods comparatively pure thymidine, deoxyuridine, hypoxanthine deoxyriboside and guanine deoxyriboside were isolated. When bacterial action was allowed to proceed in the absence of toluene the corresponding free bases were isolated.

A nucleoside phosphorylase was also prepared from salmon livers ${ }^{7}$. Livers were employed since preliminary experiments indicated that livers were more active than kidney or spleen, and that other tissues (except muscle) studied possessed no such activity.

Crude extracts of salmon liver $\left(1\right.$ to 3 of $\mathrm{H}_{2} \mathrm{O}$ ) possessed specific activties ( $\mu$ moles formed per $\mathrm{mg}$ of protein $\mathrm{N}$ per hour at $37^{\circ} \mathrm{C}$ ) of $1.6-1.7$ with thymine and deoxyribose 1-phosphate.

A simple enzyme preparation activated all of the deoxynucleosides and nucleosides tested in presence of $\mathrm{Pi}$. The comparative activity was as follows in order of decreasing effectiveness: deoxyuridine $>$ thymidine $>$ deoxyguanosine $>$ deoxycytidine $>$ deoxyinosine $>$ deoxyadenosine $>$ uridine $>$ cytidine $>$ adenosine $>$ inosine $>$ guanosine $>$ xanthosine. The enzyme preparation also contained both phosphoribomutase and phosphodeoxyribomutase activities. The nucleoside phosphorylase was thus an enzyme (or enzymes) with a wide general activity spectrum that included a variety of purines and pyrimidines and of ribose 1-phosphate and deoxyribese 1-phosphate.

During earlier work on MAILLARD browning reactions the importance of the sugars ribose and glucose in causing these reactions was established. An investigation concerning the origin and distribution of sugars, sugar phosphates, nucleotides and related compounds was therefore undertaken ${ }^{8)}$. An ion exchange method was worked out whereby the normally-occurring amounts of these substances could be wellseparated. Radioactive tracer techniques were used. Many of the compounds eluted from the column (sugar phosphates especially) were prepared as lithium salts in order that they could be properly identified and the constancy of their radioactivities checked during further purification.

It was found that the amounts of sugar phosphates and nucleotides in muscles of different fish were very variable indeed as might be expected since one is dealing with complex equilibria with different enzyme systems participating. As an example the amount of G6-P found varied from 21 to $1,100 \mu$ moles per $100 \mathrm{~g}$. R5-P was only found in two instances and in very low concentrations. Rl-P was never found, and this is not surprising since in the equilibrium in the PRM system (R5.P $\hookrightarrow$ Rl-P) the equilibrium is about $90 \%$ in favour of the more stable $5^{\prime}$ compound. 
As a result of work involving addition of $\mathrm{C}^{14}$-labeled fish muscle glycogen and uniformly labeled $\mathrm{C}^{14}$ ATP to fish muscle the following conclusions were drawn. Gly. cogen is degraded post mortem via two pathways, namely the EMBEDEN-MYeRHoF glycolytic route and by an amylolytic route. The latter appears to be favoured by autolysis and blending of the muscle and therefore it is thought that the enzymes concerned possibly reside in particulate cell matter. All evidence indicated that the main nucleotides (AMP and IMP), R5-P and free ribose are derived from ATP. RNA degradation has not yet been demonstrated. The problem appears to be rather involved since studies by TOMLINSON and his collaborators in this laboratory indicate that added RNA may be degraded, but that RNA as it exists in the muscle itself is not degraded appreciably post mortem. In is suggested that RNA in fish muscles may be bound to protein (as with HAMOIR's nucleotropomyosin) and this is inaccessible to ribonuclease. There appears to be only very slight hydrolysis of G6. $P$ to yield glucose and all our evidence indicates that the fructose monophosphate in fish muscles is largely or entirely F6-P. The formation of sugars and sugar phosphates in fish muscles post mortem probably occurs as follows (Fig. 1).

There has been considerable uncertainty whether or not the oxidative pentose phosphate pathway is operative in live fish muscle or other tissues. Present evidence indicates that normally that EMBDEN-MYERHOF route is the main pathway of carboxy. hydrate metabolism in fishes, and that the pentose phosphate pathway becomes operative only under special circumstances, as when fish are cold-acclimated or are kept under anaerobic conditions for some hours.

Since the glucose dehydrogenase and lactonase enzymes that are involved in the initial stages of operation of the pentose phosphate pathway carry out reactions which are probably largely irreversible in their role in forming 6-phosphogluconic acid, it was thought tnat a study of the metabolism of $\mathrm{C}^{14}$-labeled 6-phosphogluconic acid in fish might indicate whether or not the pentose cycle is operative ${ }^{9 j}$.

Trout, Salmo gairdnerii, were injected intraperitoneally or intramuscularly with GL (generally labeled) $\mathrm{C}^{14}$ glucose or 6-phosphogluconate (6PG) and kept under conditions where the respired $\mathrm{C}^{14} \mathrm{O}_{2}$ was trapped in $\mathrm{NaOH}$. The results showed that $\mathrm{C}^{14} \mathrm{O}_{2}$ was formed 50 to 75 times as fast from $C^{14}$ glucose as from $C^{14} 6 P G$. The rate of $\mathrm{C}^{14} \mathrm{O}_{2}$ formation from $6 \mathrm{PG}$ was the same when fish were injected with $\mathrm{C}_{1}, \mathrm{C}_{6}$ or $\mathrm{GL}$ $\mathrm{C}^{14} 6 \mathrm{PG}$. Intramuscular or intravenous injection of $\mathrm{C}_{6} \mathrm{C}^{14} 6 \mathrm{PG}, \mathrm{C}_{1} \mathrm{C}^{14} 6 \mathrm{PG}$ or $\mathrm{GLC}^{14}$ gluconic acid (GA) caused radioactivity to appear in the "dextrin", maltose, glucose, G6P, F6P, FDP and GA of the fish tissues. On the contrary, maltose, glucose, and the hexose-phosphates were either not radioactive, or had extremely low specific activities, when the fish were injected with $\mathrm{C}_{1} \mathrm{C}^{14} 6 \mathrm{PG}$. These facts are consistent with slow metabolism of $6 \mathrm{PG}$ via the pentose phosphate pathway in living fish.

GA of fairly high specific activity was found in fishes injected with $C^{14} 6 P G$, and $\mathrm{C}^{14}$-labeled hexose phosphates were found in fish injected with $\mathrm{C}^{14} \mathrm{GA}$, and it was 


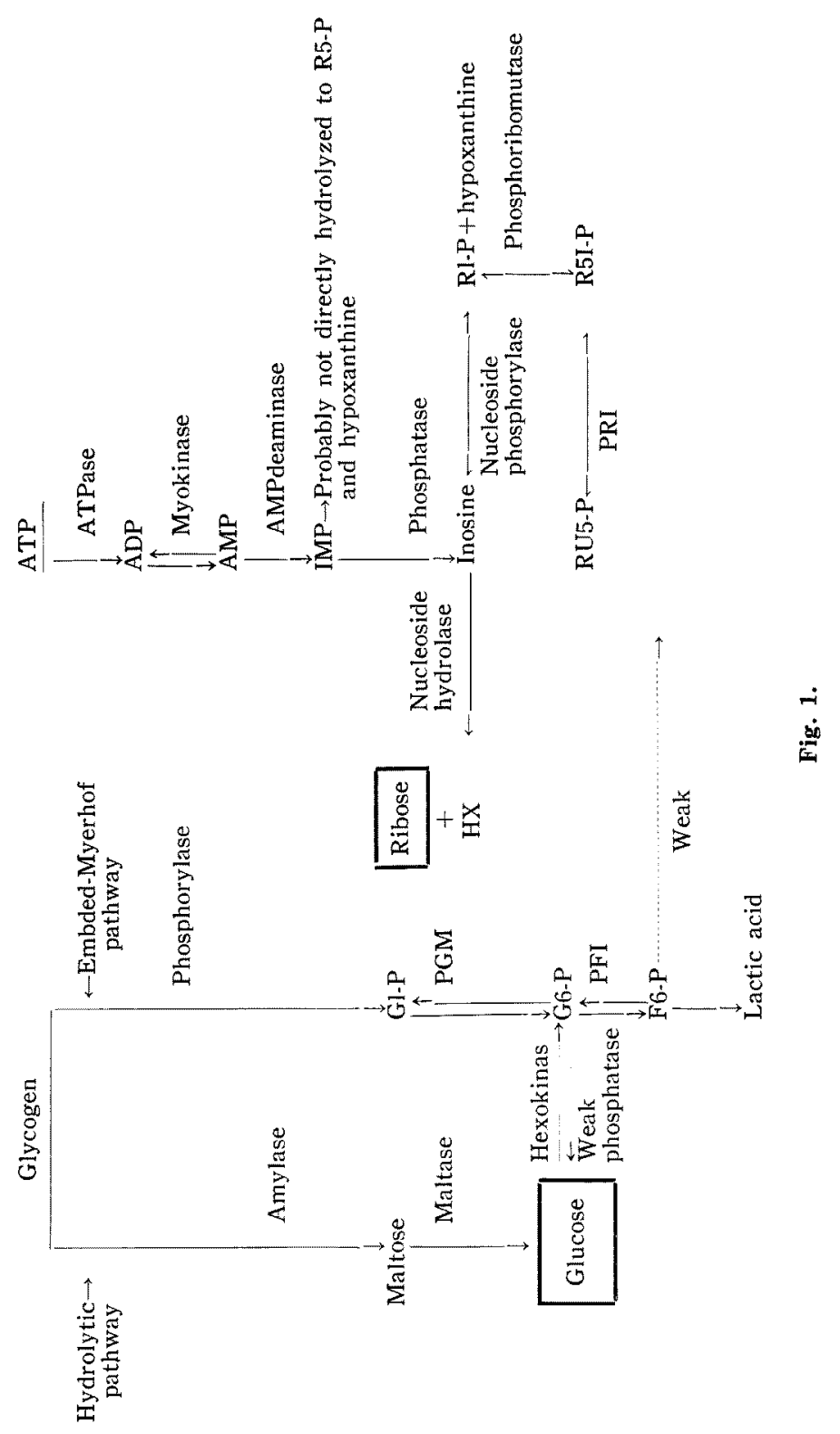


therefore concluded that live fish can liberate orthophosphate from 6PG and can phosphorylate GA. It was suggested that, at least until the rate of $\mathrm{C}^{14} \mathrm{O}_{2}$ formation from radioactive $6 \mathrm{PG}$ has been studied with tissues known to utilize either the pentose phosphate or Embden-Myerhof pathways of glucose metabolism, it will be impossible to place any quantitative interpretation on results of experiments in which $6 \mathrm{PG}$ or GA are used.

During the past two years a study on the mechanism of biosynthesis of DNA in male gonads (milts) of salmon has been carried out, and is still in progress. In preliminary studies the milts available were somewhat too mature, and in recent studies less mature milts have been used with much better results. In the preliminary work in several instances the milts of live sockeye salmon were injected directly and the fish were then sewn up and held several days before the milts were excised and examined. However, it was soon found that excised milts could be used directly (in vitro experiments), and most experiments were carried out by injecting them with a radioactive compound and holding them 2 to 4 days at $0^{\circ} \mathrm{C}$ or 2.5 or 4 hours at $30^{\circ} \mathrm{C}$.

In general, incorporation of radioactivity in these experiments was rather poor, and subsequent work has shown that this was undoubtedly due to the rather advanced state of maturity of the milts. Greater success has attencled recent work (see below) in which much less mature milts were used. The results, however, showed that $\mathrm{C}^{14}$. labeled adenine, guanine and tritiated thymidine were incorporated in the DNA, and that the injected bases were incorporated as such with no cross-labeling of other bases ${ }^{10)}$. In these experiments cytosine was also apparently incorporated, though this has not been confirmed in more recent experiments (see below).

A study was made of several cell-free enzyme systems that are probably implicated in formation of DNA in milts.

Reaction mixtures containing tritiated $\mathrm{P}$-ribose-PP, $\mathrm{C}^{14}$-labeled purine, pyrimidine or orotic acid, $\mathrm{MgCl}_{2}$, Tris-HCl buffer $\mathrm{pH} 8.0$ and cell-free milt enzyme were incubated 4 hours at $35^{\circ} \mathrm{C}^{11}$. The expected mononucleotides were added as carriers and these were isolated by appropriate column and paper chromatographic methods. Radioactive AMP, GMP, IMP, TMP, CMP and UMP were isolated from the reaction mixtures. Both uracil and orotic acid yielded UMP.

Since the above nucleotides would presumably be formed by the following general reaction: $\mathrm{H}^{3}$ P-ribose-P.P $+\mathrm{C}^{14}$ purine or pyrimidine base $\rightarrow$ mononucleotide $\left(\mathrm{C}^{14}+\right.$ $\mathrm{H}^{2}$ labeled) $+\mathrm{PP}$, it would be expected that the ribose moiety would be tritiated and the base $\mathrm{C}^{14}$ labeled. This was verified by acid hydrolysis of the purine nucleotides to yield the corresponding $\mathrm{C}^{14}$ labeled free bases and tritiated D-ribose. This experiment showed that salmon milt extract contains an active pyrophosphorylase enzyme capable of forming ribomononucleotides from PRPP and purine or pyrimidine bases.

Another possible route of formation of mononucleotides is by the combined ac- 
tion of nucleoside phosphorylase and nucleoside kinase enzymes:

(1) Base $+\mathrm{Rl}-\mathrm{P}$ (or d-Rl-P) $\rightleftarrows$ nucleoside (or deoxynucleoside) $+\mathrm{Pi}$

(2) Nucleoside (or deoxynucleoside) $+\mathrm{ATP} \rightarrow$ nucleotide (or deoxynucleotide) $+\mathrm{PP}$

Using radioactive purines or pyrimidines, nucleosides and deoxynucleosides, and Rl-P or d-Rl-P and the cell-free milt enzyme the following results were obtained ${ }^{12)}$.

1. Radioactive ribo- or deoxyribomononucleotides were formed from the corresponding nucleoside in presence of ATP. Thus AMP, UMP, GMP, CMP, d-UMP and d-TMP were synthesized. 2. Both nucleosides and mononucleotides were formed from purine and pyrimidine bases in presence of ATP and Rl-P. Thus guanine yielded guanosine and GMP, uracil and orotic acid yielded uridine and UMP. When dRl-P was substituted for Rl-P, the corresponding deoxynucleosides and deoxymononucleotides were formed. Biosynthesis of the following compounds was thus accomplished with the soluble milt enzyme preparation: GR, GdR, CR, CdR, TR, TdR, UR, UdR, HXR, HXdR and nearly all of the corresponding mononucleotides. 3 . Radioactive ribose and deoxyribose were recovered by hydrolysis of the purine ribonucleosides (or deoxyribonucleosides) synthesized as in (2) above. 4. Both radioactive thymine riboside and thymine deoxyriboside (thymidine) were prepared in small amounts and identified.

We have recently prepared from salmon milts a cell-free nucleotide kinase enzyme of wide specificity ${ }^{13)}$. The enzyme was very unstable. Thus, biosynthesis of CTP from CMP was reduced by about $66 \%$ when the enzyme preparation was held 1 hour at $30^{\circ} \mathrm{C}$, and $85 \%$ in 2 days at $0^{\circ} \mathrm{C}$.

The enzyme had an sbsolute requirement for ATP, which could be replaced to some extent by GTP, CTP, UTP, ITP and TTP. The enzyme utilized a number of nucleoside (or deoxynucleoside) monophosphates in presence of ATP to yield the corresponding nucleoside di- and triphosphates. CMP, AMP, UMP and d-AMP were utilized most effectively, GMP, d-CMP less effectively and TMP and IMP very feebly. The reaction was accelerated by $\mathrm{Mg}^{++}, \mathrm{Ca}^{++}, \mathrm{Mn}^{++}, \mathrm{Co}^{++}, \mathrm{Ni}^{++}$and $\mathrm{CN}^{-}$, and was inhibited by $\mathrm{Cu}^{++}, \mathrm{Ag}^{++}, \mathrm{Zn}^{++}, \mathrm{Hg}^{++}$, EDTA, iodoacetate, $p$-OH-mercuribenzoate and $\mathrm{KF}$.

Nucleoside diphosphates alone yielded both nucleoside triphosphates and nucleoside monophosphates in absence of added ATP. CTP was slowly degraded to CDP and CMP, and UTP to UDP, but not to UMP, indicating slow phosphatase activity. These results indicated that both nucleoside triphosphate-nucleoside monophosphokinase, and nucleoside diphosphokinase activities were present. So far attempts to demonstrate reduction of nucleoside diphosphates to deoxynucleoside diphosphates have been unsuccessful.

Recent work (TARR, unpublished) has shown that if slices of very immature milts from Salmo gairdnerii (200-2000 $\mathrm{mg}$ in weight and rather transluscent) are used, incorporation of radioactivity into DNA is much more readily accomplished. While 
excellent incorporation of $\mathrm{TdR}, \mathrm{GdR}$ and $\mathrm{AdR}$ into the thymine, guanine and adenine of the milt DNA is obtained if freshly sliced tissues is used, homogenizing, freezing in liquid nitrogen and thawing, or incubating in vacuo cause inactivation. This may be due (or partly due) to liberation of a neutral type of DNAse (DNAse I). By this method the bases in DNA have been successfully labeled with a variety of free bases nucleosides and related compounds. Radioactive glucose is incorporated, and this appears also to be true of P-ribose-pp and R5-P.

Experiments have demonstrated that fish muscle AMP deaminase is much more heat labile than adenosine deaminase, and that therefore the two activities are presumably distinct ${ }^{14}$. Using a partially purified enzyme preparation from lingcod muscle that possessed both adenosine deaminase and deoxynucleoside phosphorylase activities the following relationships were established:

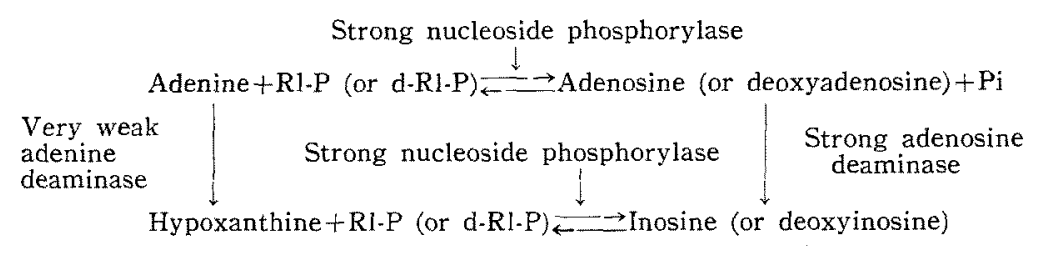

Thus formation of inosine (or deoxy-inosine) from adenine proceeds actively via adenosine (or deoxyadenosine), the very limited rate of formation of hypoxanththine making the alternative route very minor indeed.

The occurrence of ribose, glucose, homarine and nucleotides has been demonstrated in shrimp muscle ${ }^{157}$.

\section{References}

1) TARr, H. L. A.: The acid-soluble phosphorus compounds of fish skeletal muscle. J. Fish. Res. Bd. Canada, 7, 608 (1950).

2) TARR, H. L. A.: Fish muscle riboside hydrolases. Biochem. J., 59, 386 (1955)

3) TARr, H. L. A.: Lingcod muscle purine nucleoside phosphorylase. Can. J. Biochem. Physiol., 36, 517 (1958).

4) Bluhm, H. M. and TARr, H. L. A.: Marine fish muscle nucleic acids. Can. J. Biochem. Physiol., 35, 767 (1957).

5) Martin, G. B. and TARR, H. L. A.: Phosphoglucomutase, phosphoribomutase, and phospho* glucoisomerase of lingcod muscle. Can. J. Biochem. Physiol., 39, 297 (1961).

6) TARr, H. L. A.: Lingcod muscle phosphoriboisomerase and ribulose $5^{\prime}$ phosphate $3^{\prime}$ epimerase. Can. J. Biochem. Physiol., 37, 961 (1959).

The enzyme 5-phosphoryIribose pyrophosphokinase in fish muscle. Can. J. Biochem. Physiol., $38,683(1960)$.

7) TARr. H. L. A. and Mannan, A.: Preparation of deoxynucleosides, purine and pyrimidine bases and deoxyribose 1-phosphate from deoxyribonucleic acid employing salmon enzyme systems. J. Fish. Res, Bd. Canada, 18, 349 (1961).

8) TARr, H. L. A. and Leroux, M.: Acid-soluble phosphorus compounds and free sugars in fish muscle and their origin. Can. J. Biochem. Physiol., 40, 571 (1962).

9) TARR, H. L. A.: Metabolism of 6-phosphogluconic acid and gluconic acid in Salmo gairdneriz. Can. J. Biochem. Physiol., 41, 313 (1963). 
10) TARR, H. L. A.: Incorporation of radioactive purine bases and of thymidine into the deoxyribonucleic acid of salmon milts. Can. J. Biochem., 42, 51 (1964).

11) TARr, H. L. A.: Formation of ribomononucleosides from purine and pyrimidine bases and 5'-phosphoribosylpyrophosphate by a salmon milt enzyme extract. Can. J. Biochem., 42575 (1964).

12) TARR, H. L. A.: Formation of purine and pyrimidine nucleosides, deoxynucleosides, and the corresponding mononucleotides by salmon milt extract nucleoside phosphorylase and nu* cleoside kinase enzymes. Can. J. Biochem., 42, 1535 (1964).

13) TARR, H. L. A. and ROY. JOAN.: Synthesis of nucleoside diphosphates and triphosphates by a salmon milt enzyme preparation. Can. J. Biochem., (in press, 1965).

14) TARr, H. L. A. and Comer, A. G.: Deamination of adenine and related compounds and formation of deoxyadenosine and deoxyinosine by lingcod muscle enzymes. Can. J. Biochem., 42, 1527 (1964).

15) TARr, H. L. A. and COMER, A. G.: Nucleotides and related compounds, sugars, and homarine in shrimp. J. Fish. Res. Bd. Canda, 22, 307 (1965). 